\title{
Structural Stability of Amorphous Alloy of Modified Finemet Type
}

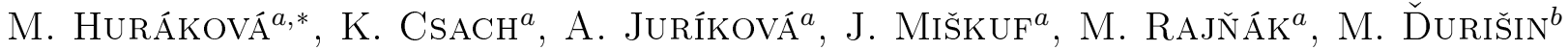 \\ AND T. KVAČKAJ ${ }^{c}$ \\ ${ }^{a}$ Institute of Experimental Physics, Slovak Academy of Sciences, Watsonova 47, 04001 Košice, Slovakia \\ ${ }^{b}$ Institute of Materials Research, Slovak Academy of Sciences, Watsonova 47, 04001 Košice, Slovakia \\ ${ }^{c}$ Department of Metal Forming, Faculty of Metallurgy, Technical University of Košice, \\ Vysokoškolská 4, 04200 Košice, Slovakia
}

\begin{abstract}
The Finemet type amorphous alloys are well known as high frequency soft magnetic materials. They have good soft magnetic properties which are characterized by low coercive force and high permeability because of the lack of crystalline anisotropy. The structural stability of the amorphous ribbon of Finemet type modified by Mn, $\mathrm{Al}$ and $\mathrm{Cr}$ prepared by melt-spinning process was studied using differential scanning calorimetry and dynamical mechanical analysis. With increase of the crystalline portion in the sample, the Curie transition is shifted to the higher temperatures. The magnetic relaxation processes at frequencies above $10^{4} \mathrm{~Hz}$ were detected by mass magnetic susceptibility measurement.
\end{abstract}

DOI: $10.12693 /$ APhysPolA.127.564

PACS: 61.43.Dq, 62.20.Hg, 62.20.de

\section{Introduction}

Amorphous materials are characterized by a lack of long-range atomic arrangement similar to that of liquid state. The lack of crystallinity causes very low anisotropy of amorphous alloys based on random anisotropy model [1]. Finemet type alloys with optimum $\mathrm{Fe}-\mathrm{Cu}-\mathrm{Nb}-\mathrm{Si}-\mathrm{B}$ composition are well known as high frequency soft magnetic materials that are obtained by amorphization of rapid quenching of melt and subsequent crystallization during heat treatment at temperatures from about $500{ }^{\circ} \mathrm{C}$ to $600{ }^{\circ} \mathrm{C}$. Optimum mechanical and magnetic properties of the nanocrystalline soft magnetic materials are obtained after a partial crystallization of their amorphous precursors. In these alloys silicon and boron are so-called glass-forming elements that help forming the amorphous state of the alloy and increase the thermal stability of the amorphous phase [2-4].

Finemet system usually consists of very fine nanocrystalline $\alpha-\mathrm{Fe}(\mathrm{Si})$ grains of sizes about $10 \mathrm{~nm}$ with random texture which are surrounded by an amorphous matrix $[5,6]$. The chemical composition and heat treatment of the alloy influence on the formation nanocrystalline nuclei in the amorphous matrix. This process is related to the processes of structural relaxation of amorphous state during heating to the temperatures lower than the crystallization temperature. Some magnetic properties as for example the Curie transition temperature $\left(T_{\mathrm{c}}\right)$ are structurally sensitive. The study of $T_{\mathrm{c}}$ changes during the relaxation may lead to a better understanding

\footnotetext{
*corresponding author; e-mail: hurakova@saske.sk
}

of the process of clustering in the amorphous phase preceding formation of the nanocrystalline structure. The changes of the Curie temperature reflect also the process of atomic redistribution which occurs just before or in the very early stage of the crystallization $[7,8]$. The observation of the Finemet alloys by direct creep measurements during the crystallization pointed to that the residual amorphous phase undergoes intensive structural relaxation at relatively high temperatures which causes the obvious embrittlement of these materials $[9,10]$. The substitution of $\mathrm{Fe}$ in the original finemet formula by $\mathrm{Mn}$ enhances the magnetic softness [11], the addition of $\mathrm{Cr}$ tends to slightly smaller nanocrystalline grain size [12] and a small amount of $\mathrm{Al}$ reduces the magnetocrystalline anisotropy and hence the coercivity [13]. We focus on the study of the amorphous structure stability of the modified Finemet type ribbon.

\section{Experimental}

A ribbon of $\mathrm{Fe}_{72.2} \mathrm{Mn}_{0.2} \mathrm{Cr}_{0.1} \mathrm{Al}_{1} \mathrm{Si}_{13.5} \mathrm{~B}_{9} \mathrm{Nb}_{3} \mathrm{Cu}_{1}$ (at.\%) of about $40 \mu \mathrm{m}$ thick has been prepared by melt-spinning technique. The structure of the ribbon was investigated by X-ray diffraction (XRD) using the Philips X'Pert Pro diffractometer equipped with $\mathrm{Cu}$ cathode at operating parameters of $40 \mathrm{kV}$ and $50 \mathrm{~mA}$.

Differential scanning calorimetry (DSC) measurements were performed at the rate of $10^{\circ} \mathrm{C} / \mathrm{min}$ in the flowing nitrogen atmosphere using DSC Q2000-TA Instruments apparatus. The sample was heated in ten subsequent heating runs up to different final temperatures $\left(T_{\mathrm{f}}\right)$ in the range $370-550^{\circ} \mathrm{C}$. This interval was chosen for distinguishing the influence of the structural relaxation and the crystallization effect. 
The changes of the complex mechanical modulus were studied by dynamic mechanical analysis (DMA) using TMA Q400EM TA Instruments. In order to probe dynamic magnetic properties the induction technique IMEGO DynoMag AC Susceptometer was used.

\section{Results and discussions}

The XRD pattern of the prepared sample is presented in Fig. 1. The pattern displays a broad maximum centered approximately at $2 \theta=44^{\circ}$ that is characteristic for the amorphous phase. The XRD experiment confirmed that in the glassy matrix there is present a small volume fraction of unidentified crystalline precipitates.

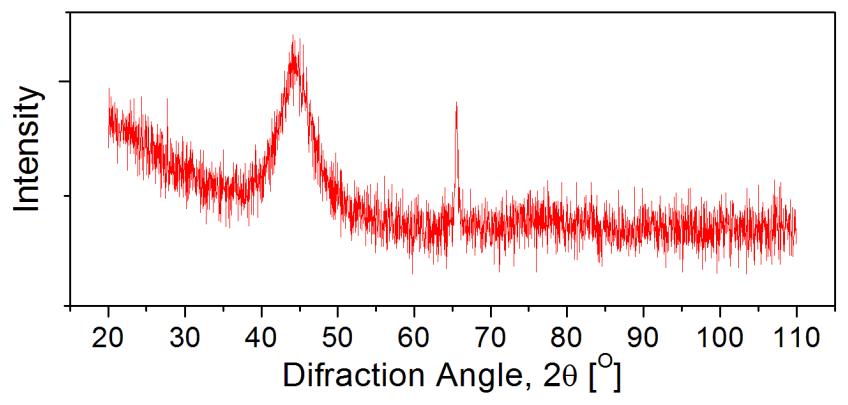

Fig. 1. XRD pattern of the modified Finemet type alloy with the narrow crystalline peak.

The structural changes and their influence on the Curie transition temperature values of the alloy were studied by DSC method. DSC traces for subsequent heating runs can be seen in Fig. 2.

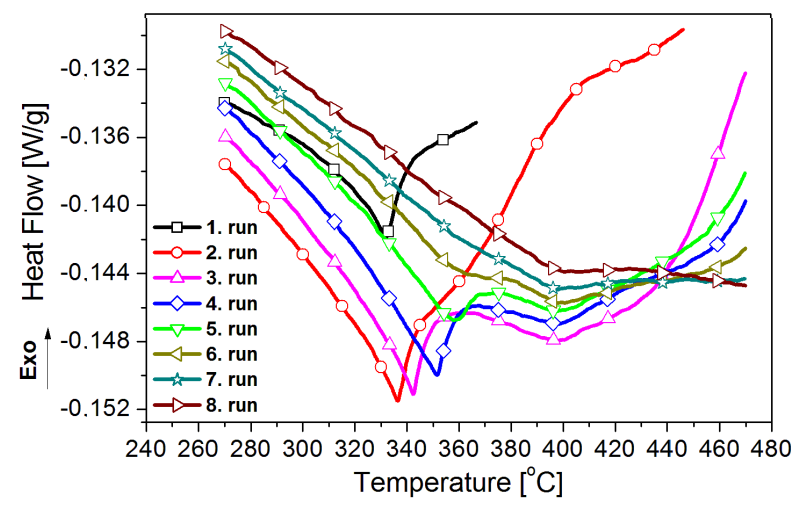

Fig. 2. DSC traces of the observed alloy during subsequent heating runs.

During the first heating run (the sample is in asquenched state) the sharp peak corresponding to the Curie temperature $T_{\mathrm{c} 1}$ is visible. At the second run the DSC trace differs from that one in the first run due to the partially overcame structural relaxation in the sample during heating up to $370^{\circ} \mathrm{C}$ in the first run. The structural relaxation is connected with exothermic free volume annihilation processes [14].
While the structural relaxation occurs, the generated heat flow decreases with subsequent runs. Beginning from the third run the additional broader minimum is visible on the DSC traces. This peak is connected with the Curie transition at the temperature $T_{\mathrm{c} 2}$ of the crystalline phase that is present in the prepared sample. Therefore the position of $T_{\mathrm{c} 2}$ depends on the thermal history of the sample only slightly. The Curie temperatures $T_{\mathrm{c} 1}$ and $T_{\mathrm{c} 2}$ determined from DSC measurements for individual structural states are summarized in Table.

\section{TABLE}

Curie transition temperatures $T_{\mathrm{c} 1}$ and $T_{\mathrm{c} 2}$ for different structural states. The temperature $T_{\mathrm{f}}$ is the final temperature of the heating run.

\begin{tabular}{c|c|c|c}
\hline \hline Run & $T_{\mathrm{c} 1}\left[{ }^{\circ} \mathrm{C}\right]$ & $T_{\mathrm{c} 2}\left[{ }^{\circ} \mathrm{C}\right]$ & $T_{\mathrm{f}}\left[{ }^{\circ} \mathrm{C}\right]$ \\
\hline 1 & 332.0 & - & 370 \\
2 & 336.5 & - & 450 \\
3 & 342.4 & 397.8 & 500 \\
4 & 351.7 & 398.1 & 510 \\
5 & 358.7 & 398.2 & 520 \\
6 & 363.6 & 398.6 & 530 \\
7 & 369.8 & 398.9 & 540 \\
8 & - & 399.4 & 550 \\
9 & - & 399.5 & 550 \\
10 & - & 399.7 & 550
\end{tabular}

The exothermic effects at temperatures above $440{ }^{\circ} \mathrm{C}$ connected with the crystallization of the amorphous phase decrease with repeated heatings.

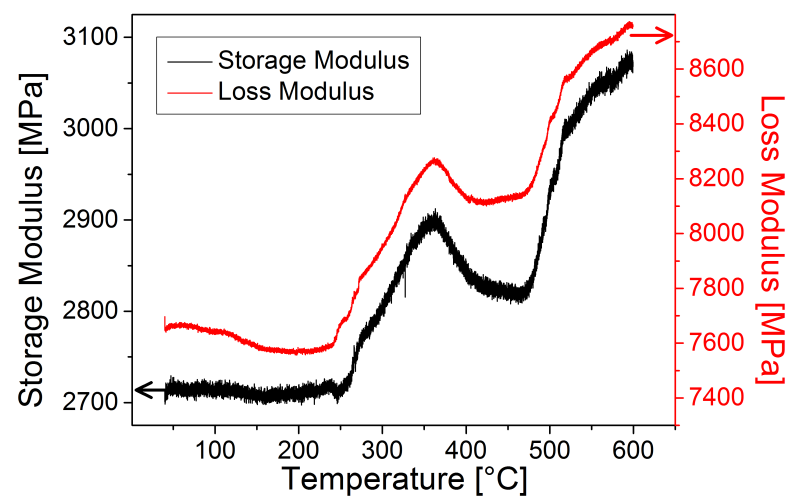

Fig. 3. The temperature dependences of the components of the complex elastic modulus.

The changes of the complex elastic modulus during heating and the progressing structural relaxation of the alloy was characterized by DMA analysis as can be seen in Fig. 3. DMA measurements were performed at heating up to $600{ }^{\circ} \mathrm{C}$ at the rate of $2{ }^{\circ} \mathrm{C} / \mathrm{min}$ under harmonic loading of $0.2 \mathrm{~N}$ with the frequency of $1 \mathrm{~Hz}$ and the preloading force of $0.3 \mathrm{~N}$. The sample dimensions were $16 \mathrm{~mm}$ (length), $2 \mathrm{~mm}$ (width) and $0.04 \mathrm{~mm}$ (thickness). At temperatures up to about $250^{\circ} \mathrm{C}$ the storage and loss modulus remain nearly constant. At temperatures above 
$250^{\circ} \mathrm{C}$ the mechanical hardening is observed. It is related to the gradually flowing structural relaxation linked with the free volume annihilation. The change to the softening above the temperature of $350{ }^{\circ} \mathrm{C}$ can be connected with vanishing the magnetoelastic interaction above the Curie transition of the amorphous phase. Next magnetic transition at about $400{ }^{\circ} \mathrm{C}$ is visible on the temperature dependences of the modulus.

Magnetic susceptibility of the Finemet type amorphous alloy was measured at room temperature as Fig. 4 shows. The isothermal AC susceptibility was measured in the frequency range from $1 \mathrm{~Hz}$ up to $250 \mathrm{kHz}$ with the magnitude of the excitation field $5 \mathrm{mT}$ falling off from $1 \mathrm{kHz}$ to higher frequencies. As the real and imaginary susceptibility values are approximately constant in the low frequency range, the magnetization is able to follow the changes in the $\mathrm{AC}$ excitation field. However, when approaching $10^{4} \mathrm{~Hz}$, the clear decrease in the real part appears and the onset of a loss maximum starts to form.

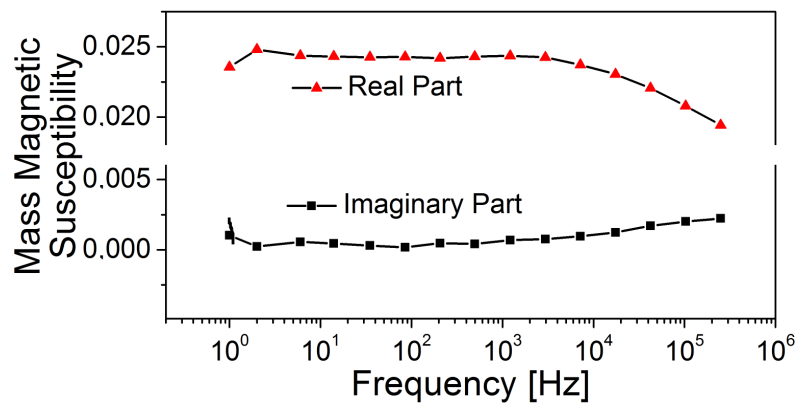

Fig. 4. The frequency dependence of the magnetic mass susceptibility.

This change is related to a magnetic relaxation process. Nevertheless, for unambiguous interpretation one needs to measure the susceptibility in the extended frequency range where the related relaxation time could be detected.

\section{Conclusion}

We studied the structural stability of Finemet type amorphous alloy modified by $\mathrm{Mn}, \mathrm{Al}$ and $\mathrm{Cr}$ elements with small amount of crystalline phase. The changes of Curie transition temperatures related to the magnetic transitions in the amorphous and the crystalline phase were detected by DSC analysis. During repeated heating to gradually increased temperatures, Curie temperature of the amorphous phase gradually increases, while the magnetic transition in the crystalline phase is shifted to the higher temperatures only slightly. DMA analysis revealed the influence of magnetoelastic phenomenon during stabilization and crystallization of the amorphous structure. Measured frequency dependence of the magnetic mass susceptibility showed the increased magnetic relaxation at frequencies above $10^{4} \mathrm{~Hz}$.

\section{Acknowledgments}

This work was supported by the Slovak Academy of Sciences - VEGA 2/0045/14, by Slovak Research and Development Agency - contract No. APVV-0171-10 and by the projects Nos. 26220120033 and 26110230097 provided in the frame of structural funds of the European Union.

\section{References}

[1] R. Alben, J.J. Becker, M.C. Chi, J. Appl. Phys. 49, 1653 (1978).

[2] Y. Yoshizawa, S. Oguma, K. Yamauchi, J. Appl. Phys. 64, 6044 (1988).

[3] T. Kulik, J. Non-Cryst. Solids 287, 145 (2001).

[4] G. Herzer, J. Magn. Magn. Mater. 112, 258 (1992).

[5] S. Mahmud, Asian Trans. Sci. Technol. 1, 2221 (2011).

[6] U. Köster, U. Schünemann, M. Blank-Bewersdorff, S. Brauer, M. Sutton, G.B. Stephenson, Mater. Sci. Eng. A 133, 611 (1991).

[7] A.L. Greer, J.A. Leake, J. Non-Cryst. Solids 33, 291 (1979).

[8] C. Miguel, S. Kaloshkin, J. Gonzalez, A. Zhukov, J. Non-Cryst. Solids 329, 63 (2003).

[9] K. Csach, J. Miškuf, A. Juríková, J. Phys. Conf. Series 200, 082002 (2010).

[10] V. Ocelík, P. Diko, V. Hajko, J. Miskuf, P. Duhaj, J. Mater. Sci. 22, 2305 (1987).

[11] R. Brzozowski, M. Wasiak, H. Piekarski, P. Sovak, P. Uznański, M.E. Moneta, J. Alloys Comp. 470, 5 (2009).

[12] A.C. Hsiao, M.E. McHenry, D.E. Laughlin, M.R. Tamoria, V.G. Harris, IEEE Trans. Magn. 37, 2236 (2001).

[13] A. Zeleňáková, M. Kuźmiński, J. Füzer, P. Kollár, T. Švec, J. Magn. Magn. Mater. 215-216, 459 (2000).

[14] J. Miškuf, K. Csach, A. Juríková, Acta Phys. Pol. A 121, 1273 (2012)

[15] J.C. Qiao, J.M. Pelletier, J. Appl. Phys. 112, 083528 (2012). 